\title{
Association between testicular microlithiasis and varicocele in infertile men: A comparative study
}

\author{
Mohamed Farid MD', Ahmed Ragab MD', Ahmed Sayed Abdel Baset MD', Dalia \\ Ramadan MSc. ${ }^{4}$, Sameh Fayek Gamal El Din MD ${ }^{1}$
}

\author{
Original \\ ${ }^{1}$ Department of Andrology and STDs, Kasr Al-Ainy, Faculty of Medicine, Cairo \\ Article \\ University, Giza
}

${ }^{2}$ Department of Andrology and STDs, Faculty of Medicine, Beni-Suef University, Beni-Suef, Egypt

${ }^{3}$ Department of Radiology, Faculty of Medicine, Beni-Suef University, Beni-Suef, Egypt

${ }^{4}$ Ministry of Health and Population, Giza, Egypt

\begin{abstract}
Introduction: To assess the rate of testicular microlithiasis (TM) noted on ultrasound examination of the scrotum in infertile patients with varicocele.

Patients and Methods: A total of 60 patients with infertility and clinical varicocele were assessed in comparison with 60 healthy fertile controls. The two groups were evaluated by history taking, clinical examination as well as semen analysis (WHO, 2010). Color Doppler ultrasonography was performed to assess the rate of TM in both groups. Finally, hormonal profile was studied for those with infertility and sperm concentration less than $10 \mathrm{million} / \mathrm{ml}$.

Results: Sonographic features of TM were revealed in 4/ 60 (6.7\%) of cases with varicocele. However, this finding was of statistical insignificance $(P=0.081)$. Of those cases, three had left varicocele associated with ipsilateral TM and one had bilateral varicocele and bilateral TM, whereas there was no sonographic evidence of TM in controls. Cases with TM were associated with primary infertility.

Conclusion: In brief, this study demonstrated that only four of the 60 patients revealed intratesticular calcifications, and this was statistically insignificant. Moreover, there were also 23 healthy controls with subclinical varicoceles that were detected by scrotal duplex. However, TM was not detected in them. Thus, association of TM with varicocele is controversial. Finally, we recommend further studies to replicate this finding and to perform studies that compare fertile men and infertile patients with varicoceles to replicate this finding.
\end{abstract}

Key Words: Color Doppler ultrasonography, infertility, testicular microlithiasis, varicocele

Received:08 February 2018, Accepted:06 October 2018

Corresponding Author: Sameh Fayek Gamal El Din MD., Department of Andrology and STDs, Kasr Al-Ainy, Faculty of Medicine, Cairo University, Giza, Egypt, Zip Code: 11956, Fax : +20 2628 884, Tel.: +20 1227109309 , E-mail: samehfayek@hotmail.com

ISSN: 2090-6048, June 2018, Vol. 8, No. 2

\section{INTRODUCTION}

Testicular microlithiasis (TM) is an uncommon condition of unknown etiology present as multiple tiny calcifications within the seminiferous tubules ${ }^{[1-3]}$. This sonographic finding is associated with both malignant and benign conditions such as testicular neoplasms ${ }^{[4,5]}$. Fedder stated that Doherty and colleagues were the first investigators to describe the ultrasonographic (US) appearance of $\mathrm{TM}$ as small, uniform nonshadowing calcifications less than $3 \mathrm{~mm}$ randomly scattered throughout the parenchyma of the testis ${ }^{[6,7]}$. Several published studies indicate that the prevalence of TM ranges from 0.6 to $9 \%$ in symptomatic patients $^{[8-11]}$. On the contrary, Höbarth et al..$^{[12]}$ pointed out that the prevalence of TM in patients who underwent US owing to a variety of scrotal symptoms was $0.6 \%$. However, this incidence has increased in the past few years owing to technological advances and raising awareness about the condition ${ }^{[11]}$. In the same vein, Pedersen et al. ${ }^{[13]}$ found recently that the prevalence of TM in patients who had an US investigation of the scrotum owing to testicular/scrotal symptoms was $12.8 \%$. Moreover, Fedder ${ }^{[7]}$ demonstrated that the prevalence rate of testicular hyperechoic foci (sonographic $\mathrm{TML}=$ testicular microlithiasis, $\mathrm{FSH}=$ follicle stimulating hormone, $\mathrm{LH}=$ luetinizing hormone) in nonvasectomized azoospermic males is $13.4 \%$. 
Varicocele is defined as the hemodynamic impairment of testicular venous network with continuous blood reflux in pampiniform plexus and characterized by the abnormal dilation and retrograde flow in the affected veins ${ }^{[14]}$.

The incidence of varicocele is estimated to be $20-40 \%$ in infertile men, but only $15 \%$ in the general population ${ }^{[15,16]}$. It is widely accepted that idiopathic varicoceles are mainly evident on the left side ${ }^{[16]}$. However, a bilateral disease was also evident ${ }^{[17]}$. Eventually, some investigators demonstrated an association between varicocele and $\mathrm{TM}^{[17,18]}$. Unfortunately, most TM studies were retrospective with limited background information ${ }^{[13]}$. We sought in this study to evaluate prospectively the association between TM among infertile patients with varicoceles.

\section{MATERIALS AND METHODS}

\section{Study design and participants:}

This prospective study was conducted between March 2015 and June 2017 in Andrology Department, Kasr Al-Aini, Faculty of Medicine, Cairo University. A total of 60 consecutive men with infertility (group I) for at least 1 year aged 20-46 years old, who met the inclusion criteria registered below were included and compared with 60 age-matched fertile males (group II). Eligible participants signed an informed consent after providing them with a careful explanation about the study design, methods and objectives according to the regulations of Review Ethical Committee of Beni Suef Faculty of Medicine that conforms to Helsinki Declaration 1964.

\section{Inclusion criteria:}

A total of 60 primary or secondary infertile men with unilateral or bilateral varicoceles, in addition to abnormal semen parameters (oligoasthenoteratozoospermia and azoospermia) according to WHO, 2010 guidelines were enrolled in this study.

\section{Exclusion criteria:}

All infertile patients with past history of previous scrotal surgery (hydrocelectomy, orchidopexy, or testicular biopsy), testicular malignancy, scrotal infection (epididymo-orchitis and scrotal abscess), unilateral or bilateral testicular atrophy, and finally hypogonadism were excluded from this study. Moreover, patients with associated systemic illnesses, cancer, urinary tract infections, and a history of genital trauma or testicular torsion were also excluded from the study. Moreover, smokers, alcohol and/or drug abusers, and patients with occupations that impose exposure to ionizing radiations or chronic heat (cooks) were also excluded. However, two patients and two controls were enrolled in this study who had associated comorbidities (one of the two patients had chest allergy to cement and the other one had fracture of lower end of femur, whereas one of the controls had hypertension and one had bronchial asthma).

\section{Evaluation of the participants:}

Each participant was thoroughly evaluated by a comprehensive history. All the participants were exposed to general and genital examination. The testes were palpated for position, size, consistency, and contour irregularities. Physical examination is the mainstay of varicocele diagnosis ${ }^{[19]}$. All the participants provided two semen analyses with at least 2-week interval between them (WHO, 2012) to establish the diagnosis. Hormonal assay was done for those with sperm count less than 10 million/ $\mathrm{ml}$ or azoospermic. Serum hormone levels were measured using chemiluminescence immunoassay technique, with values in the range of $1.5-14 \mathrm{mIU} / \mathrm{ml}$ for FSH, $1.5-8 \mathrm{mIU} /$ $\mathrm{ml}$ for $\mathrm{LH}, 2.5-17 \mathrm{ng} / \mathrm{ml}$ for prolactin, $2.4-8.3 \mathrm{ng} / \mathrm{ml}$ for total testosterone, and $20-47 \mathrm{pg} / \mathrm{ml}$ for estradiol were taken as reference values. A morning serum sample for determination of basal hormones was obtained after 12-h fasting. Scrotal duplex US was done for all cases and controls to assess testicular and epididymal echogenicity, vascularity as well as testicular veins diameter and reflux duration in our department (MindRay 2.5 portable Doppler US). US criteria for the diagnosis of TM were the presence of at least five pinpoint hyperechoic foci of size smaller than $3 \mathrm{~mm}$ in one field view without posterior shadowing ${ }^{[8]}$. Moreover, TM was classified into classic or limited according to Bennett ${ }^{[20]}$ who classified five or more calcifications per field of view on testicular US as classic TM, and less than five calcifications per field of view on testicular US as limited TM. Scrotal US was performed in both supine and standing positions. US examination began with an assessment of testicular parenchyma, symmetry, size, and echogenicity.

The evaluation of testicular parenchyma was performed accurately. Furthermore, attention was paid to the appearance of stromal connective tissue within the so-called testicular septa. If microcalcification or macrocalcification would be found in testicular parenchyma, it was determined whether they were single, have the maximum dimension in long axes, or they were multiple and show a uniformunilateral or bilateral distribution ${ }^{[21]}$. In case that any abnormal testicular parenchymal structure was detected, we described it in terms of testicular location (upper pole, lower pole, medial border, or outer border); an assessment of the shape of the lesion, that is, regular/irregular; polycyclic outlines, with/ without clear demarcation; and finally its echogenicity (hypoechoic/isoechoic/hyperechoic). Information on the presence or absence of internal calcifications as well as the vascular pattern (peripheral vasculature of the lesion, the presence of internal vascular segments in the lesion) was also assessed ${ }^{[22]}$. We had a low threshold to do further study of the varicocele with the patient upright and/or 
with a Valsalva maneuver ${ }^{[23,24]}$. We used a color, power, or spectral Doppler US with settings optimized for lowflow velocities to aid in the diagnosis of varicoceles ${ }^{[25]}$. We used a scoring system that was published by Chiou et al. ${ }^{[26]}$ which improved the sensitivity and specificity of US in identifying clinically palpable varicoceles. Although there is a general agreement upon US appearance of varicoceles, yet there are no standardized criteria regarding the extent of venous dilation or reflux for definitive diagnosis of a varicocele ${ }^{[27]}$. Tumor markers were evaluated in cases diagnosed with TML via scrotal US.

Cases with TML underwent abdominal US and chest radiography to exclude existing extra-TM and abdominal lymphadenopathy. Despite the fact that the co-occurrence of TM with extratesticular tumors is not clear. However, the thorax and abdomen should also be radiologically examined and/or the tumor indicators such as AFP and HCG should be followed up during the routine controls to detect a new extratesticular tumor ${ }^{[28]}$. When TML was discovered by color Doppler ultrasonography (CDUS), the case completed a checklist for risk factors at the end of the US examination to decide the follow-up scheme according to the EAU recommendations ${ }^{[29]}$.

\section{Statistical analysis:}

Numerical data were expressed as minimum, maximum, and mean \pm SD. Qualitative data were expressed as frequency and percentage. The characteristics of the two groups were compared by the $\chi 2$-test for qualitative variables and the Student's t-test for quantitative variables. The IBM statistical package for the social sciences, version 20 (SPSS Inc., Chicago, Illinois, USA), was used for statistical analysis. The level of statistical significance was set as $P$ value of less than 0.05 .

\section{RESULTS}

Patients in group I $(n=60)$ had a mean age of $30.7 \pm 5.2$ years, and a mean duration of infertility of $3.1 \pm 2.6$, whereas the mean age in controls was $32.5 \pm 6.7$ years and were fertile. This difference in age was statistically insignificant $(P=0.122)$.

Of these 60 patients, $50(83.3 \%)$ had primary infertility, $10(16.7 \%)$ had fathered at least one child, $32(53.3 \%)$ were smokers, and two (3.4\%) had associated comorbidities. Overall, 20 (33.3\%) of the 60 infertile patients had left-sided varicocele only $(5,9$ and 6 patients have grades I, II and III, respectively) and $40 \quad(66.7 \%)$ had bilateral varicoceles $(9,13,16$ and 2 patients have bilateral grades I, bilateral grades III, bilateral grades II, and finally rightsided grades II and left-sided grades III, respectively) (Table 1). The controls included 60 (100\%) fertile men; $39(65 \%)$ of them were smokers and two $(3.4 \%)$ of them had associated comorbidities (Table 2). On clinical examination, varicocele could not be detected in the controls. However, their scrotal duplexes detected 30 and 23 cases with subclinical varicoceles on the right and left sides, respectively (Table 1). CDUS evaluation revealed that all fertile controls $(n=60)$ exhibited normal testicular echogenicity with no sonographic evidence of intra-TMs. On the contrary, $3 / 20(15 \%)$ of the patients with left-sided varicocele exhibited ipsilateral TM and 1/40 (2.5\%) of the patients with bilateral varicocele exhibited two-sided TM (Table 1). Infertile men with varicocele demonstrated significantly lower sperm count compared with fertile controls with varicocele $(26.1 \pm 21.4$ and $66.1 \pm 25.9$ million/ $\mathrm{ml}$, respectively, $P=0.001$; Table 3 ). Similarly, sperm total and progressive motility were significantly lower among patients with varicocele compared with fertile controls with varicocele $(34.5 \pm 22.2$ and $57.8 \pm 12.1 \%, P=0.009$, and $10 \pm 7.9$ and $41.5 \pm 5.9 \%, P=0.001$, respectively; Table 3 ). In contrast, other semen physical characteristics and sperm morphology were insignificantly different between the two groups (Table 3). The three patients within group I who displayed unilateral TM by US examination were smokers, and presented with primary infertility (infertility duration ranging between 1 and 2.5 years; Table 4).

On clinical examination, they had moderate testicular volume and clinical varicocele on the affected side (two cases with grade II varicocele and one case with grade III varicocele), with no history of medical disorders, drug intake, or prior surgeries (Table 4). Semen analysis showed severe oligoasthenozoospermia in cases 1, 3, and 4 whereas azoospermia in case 2 . All cases showed hypergonadotrophic normogonadism with normal tumor markers, abdominal US, and chest radiography (Table 4).

Table 1: Comparison between sociodemographic characteristics, spermatic cord examination, scrotal ultrasound and duplex findings of patients and controls

\begin{tabular}{|c|c|c|c|c|c|c|c|}
\hline & & $\begin{array}{l}\text { Patients } \\
(\mathrm{n}=60)\end{array}$ & & $\begin{array}{l}\text { Controls } \\
(\mathrm{n}=60)\end{array}$ & & & \\
\hline & Minimum & Maximum & Mean \pm SD & Minimum & Maximum & Mean \pm SD & Pvalue \\
\hline Age (years) & 21 & 43 & $30.7 \pm 5.2$ & 20.0 & 46.0 & $32.4 \pm 6.7$ & 0.122 \\
\hline $\begin{array}{l}\text { Infertility } \\
\text { duration } \\
\text { (years) }\end{array}$ & 0.33 & 14 & $3.1 \pm 2.6$ & - & & & - \\
\hline Nonsmoker & & $28(46.7)$ & & & $21(35.0)$ & & 0.195 \\
\hline
\end{tabular}




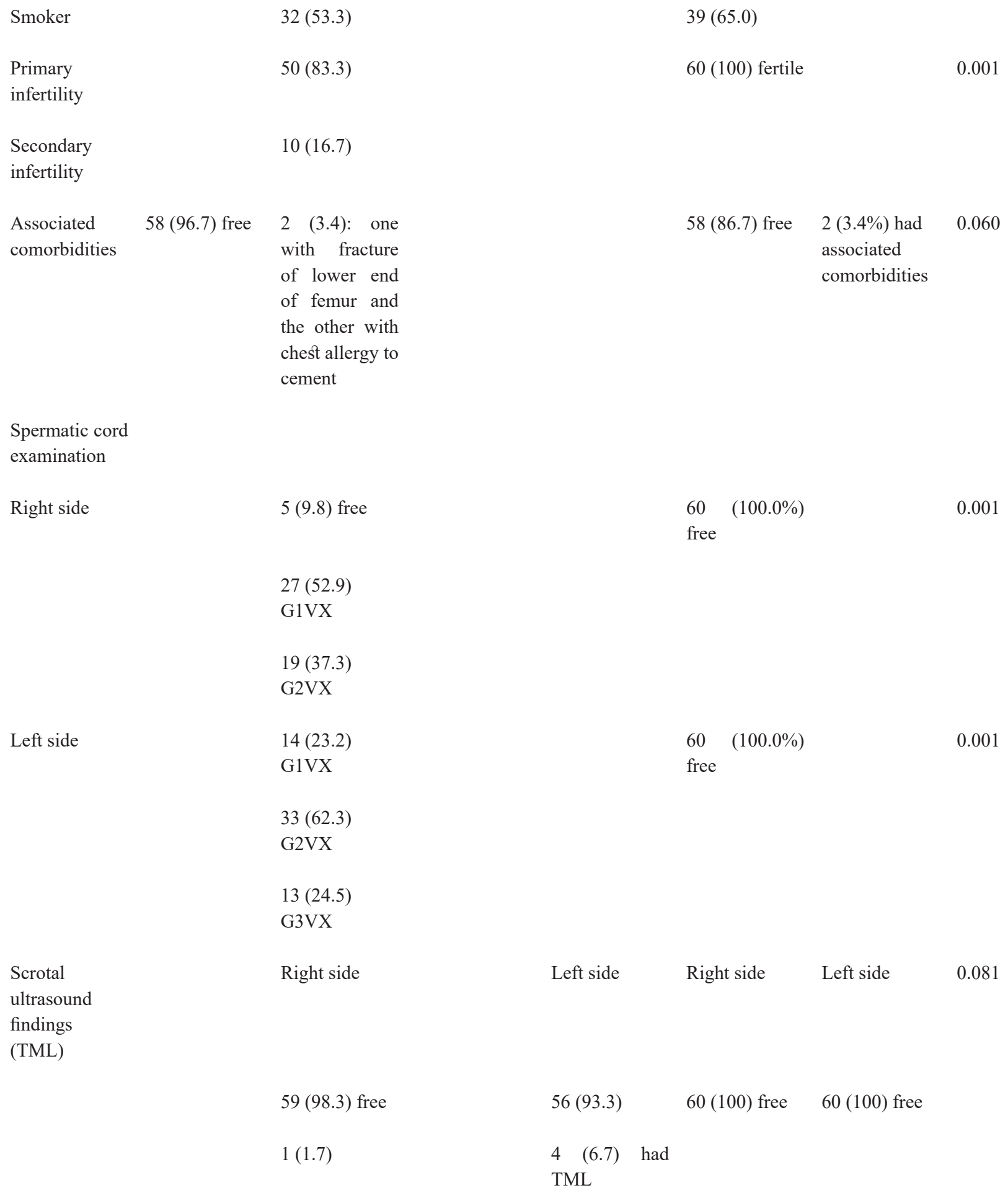

59 (98.3) free

$1(1.7)$

56 (93.3) 60 (100) free

60 (100) free

4 (6.7) had TML

Data are represented as minimum, maximum, mean $\pm \mathrm{SD}$, frequency, and percentage when appropriate. 
Table 2: Scrotal duplex findings for diagnosis of varicocele in patients and controls

\begin{tabular}{|c|c|c|c|c|c|c|c|}
\hline & \multicolumn{3}{|c|}{ Patients $(n=60)$} & \multicolumn{3}{|c|}{ Controls $(n=60)$} & \multirow[b]{2}{*}{ Pvalue } \\
\hline & Minimum & Maximum & Mean \pm SD & Minimum & Maximum & Mean \pm SD & \\
\hline $\begin{array}{l}\text { Number of } \\
\text { veins on the } \\
\text { right side }\end{array}$ & 3 & 8 & $4.5 \pm 1.4$ & 3 & 5 & $3.7 \pm 1$ & 0.158 \\
\hline $\begin{array}{l}\text { Diameter } \\
\text { of veins on } \\
\text { the right } \\
\text { side }(\mathrm{mm})\end{array}$ & 1.3 & 6.2 & $3 \pm 0.7$ & 1.2 & 3 & $2.2 \pm 0.4$ & 0.001 \\
\hline $\begin{array}{l}\text { Number of } \\
\text { veins on the } \\
\text { left side }\end{array}$ & 3 & 11 & $5.5 \pm 1.8$ & 2 & 5 & $3.5 \pm 1.1$ & 0.091 \\
\hline $\begin{array}{l}\text { Diameter of } \\
\text { veins on the } \\
\text { left side }(\mathrm{mm})\end{array}$ & 2.5 & 7 & $3.6 \pm 1.0$ & 1.2 & 3 & $2.3 \pm 0.4$ & 0.001 \\
\hline $\begin{array}{l}\text { Reflux in } \\
\text { seconds on the } \\
\text { right side (s) }\end{array}$ & 0 (negative) & 3 patients $(<1)$ & 57 patients $>1)$ & $\begin{array}{l}30 \text { patients } \\
\text { (negative) }\end{array}$ & $\begin{array}{l}30 \text { patients } \\
(<1)\end{array}$ & $0(>1)$ & 0.001 \\
\hline $\begin{array}{l}\text { Reflux in } \\
\text { seconds on the } \\
\text { left side (s) }\end{array}$ & 0 (negative) & $0(<1)$ & $\begin{array}{l}60 \text { patients } \\
(\geq 1)\end{array}$ & $\begin{array}{l}60 \text { patients } \\
\text { (negative) }\end{array}$ & 0 patients $(\leq 1)$ & $0(>1)$ & 0.001 \\
\hline
\end{tabular}

Data are represented as minimum, maximum, mean $\pm \mathrm{SD}$, frequency, and percentage when appropriate.

Table 3: Comparison between parameters of the semen analysis of the patients and the controls

\begin{tabular}{|c|c|c|c|c|c|c|c|}
\hline & \multicolumn{3}{|c|}{ Patients $(n=60)$} & \multicolumn{3}{|c|}{ Controls $(n=60)$} & \multirow[b]{2}{*}{$P$ value } \\
\hline & Minimum & Maximum & Mean \pm SD & Minimum & Maximum & Mean \pm SD & \\
\hline Volume & 0.3 & 8 & $2.7 \pm 1.6$ & 0.5 & 5 & $2.4 \pm 1.1$ & 0.245 \\
\hline Liquefaction (min) & 20 & 180 & $32.6 \pm 20.1$ & - & - & - & - \\
\hline Count $(/ \mathrm{ml})$ & 0 & 103 & $21.4 \pm 26.1$ & 16 & 115 & $66.1 \pm 25.9$ & 0.001 \\
\hline Abnormal forms (\%) & 0 & 100 & $57.7 \pm 25.5$ & 50 & 90 & $67.6 \pm 9.2$ & 0.006 \\
\hline \multicolumn{8}{|l|}{ Motility } \\
\hline Progressive (\%) & 0 & 0.35 & $10 \pm 7.9$ & 33 & 55 & $41.5 \pm 5.9$ & $0.001 * *$ \\
\hline Nonprogressive (\%) & 0 & 0.59 & $24.5 \pm 14.3$ & 5 & 30 & $16.3 \pm 6.2$ & $0.001 * *$ \\
\hline
\end{tabular}

Data are represented as minimum, maximum, mean $\pm \mathrm{SD}$. 
Table 4: Clinical examination, color Doppler ultrasonography features, and risk factors of cases with testicular microlithiasis

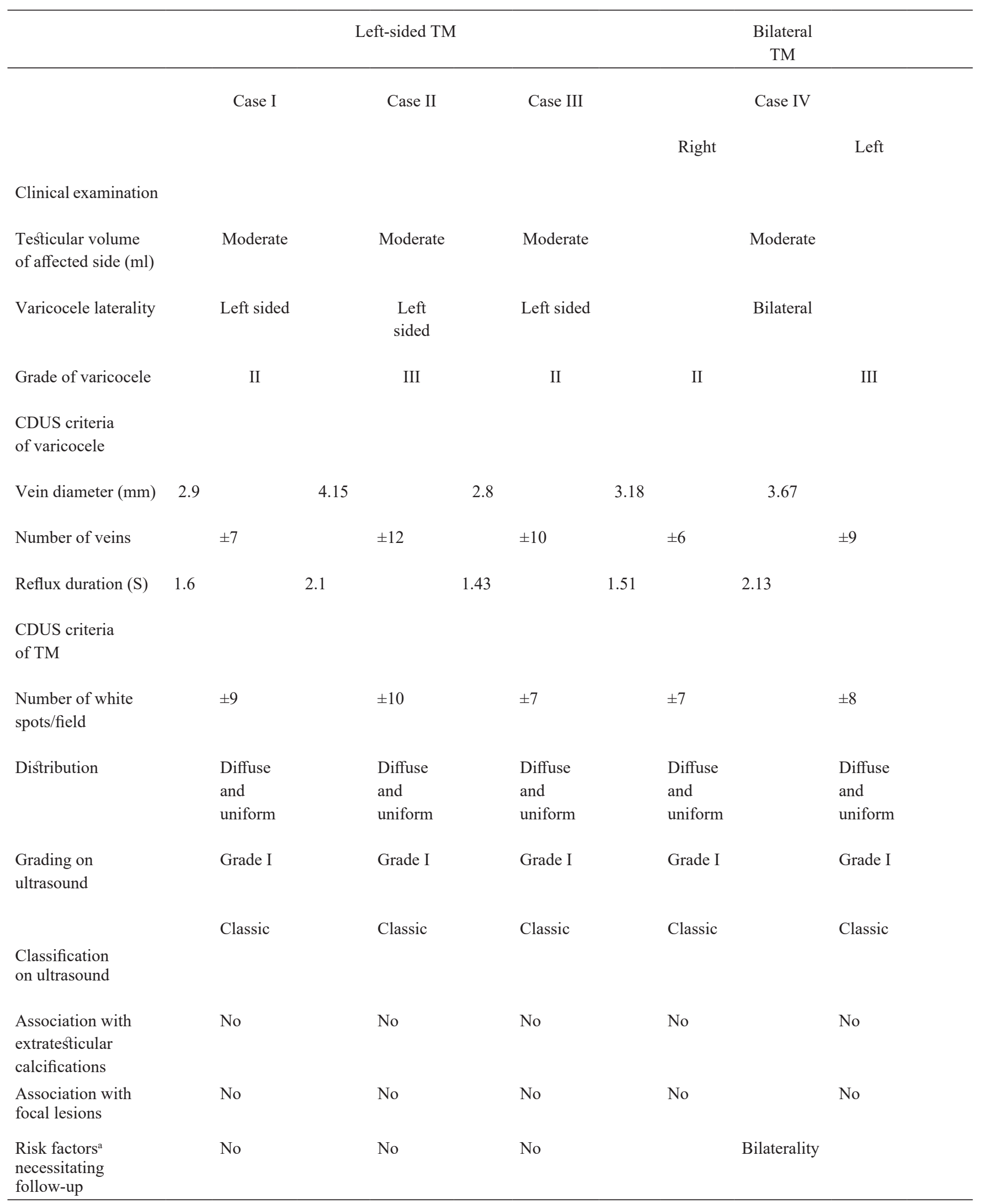

CDUS, color Doppler ultrasonography; TM, testicular microlithiasis.

${ }^{a}$ Risk factors for developing cancer include personal or family history of germ cell tumor, maldescent, orchidopexy, testicular atrophy. 


\section{DISCUSSION}

The association between varicocele and TM has been suggested by some investigators ${ }^{[10,18]}$. Xu et al. ${ }^{[30]}$ included seventeen studies concerning infertility, and the prevalence of TM in infertile men varied between 0.9 and $18.8 \%$, compared with $2.3-9.8 \%$ in studies that also included fertile men. By pooling the data, the overall prevalence of TM was 6.0 and $4.8 \%$ in infertile and fertile men, respectively $(P<0.05)^{[30]}$. On the contrary, Mahafza et al. ${ }^{[31]}$ revealed that $20.7 \%(11 / 53)$ of patients with US diagnosis of TM had associated varicocele. However, Yee et al. ${ }^{[10]}$ found that $6 \%$ of 1439 patients who underwent scrotal US had TM, but the incidence of TM in patients with varicocele was $9.8 \%$. The present study assessed prospectively the US association of TM with varicocele in infertile men. It was found that three cases with left-sided varicocele were associated with ipsilateral TM, and the only case with bilateral TM was encountered in a patient with bilateral varicocele. Additionally, all cases with sonographic diagnosis of TM were associated with either grade II or grade III varicocele. However, these findings were statistically insignificant.

Contrary to our results, a study detected $10(6.2 \%)$ cases of TM among 159 consecutive patients who had male infertility, and its finding was unilateral in all cases, and six patients had clinical evidence of a varicocele ${ }^{[32]}$. Moreover, the same study demonstrated that five cases had minimal calcification and five had marked $\mathrm{TM}^{[32]}$. Interestingly, Kobayashi et al. ${ }^{[18]}$ found that all cases with sonographic diagnosis of TM were bilateral, even if varicocele was unilateral or bilateral. Moreover, this study revealed no sonographic features of intratesticular or extratesticular scrotal calcifications in fertile controls. Recently, a potential adverse effect of TM on spermatogenesis was revealed as the investigators noticed that men with TM showed abnormal sperm morphology as well as reduced sperm motility, but normal sperm concentration. This association can be explained by the fact that calcium deposits compress the seminiferous epithelium, reducing blood supply to the testis and disrupting spermatogenesis ${ }^{[33]}$. Besides, TM is thought to have deleterious effect on the structure of blood-testis barrier with subsequent production of antisperm antibody, which is reported to have negative influence on human fertility ${ }^{[34]}$. In the same vein, our study demonstrated that infertile patients with TM showed a marked degree of semen deterioration with lower fertility potential. Moreover, the association between TM and infertility has been extensively studied with a reported prevalence of TM ranging from 2.3 to $6.2 \%$ in the infertile population ${ }^{[32,35,36]}$. Limitations of our study included the relatively low number of males with varicocele and fertile controls who underwent CDUS for assessment of TM, making it difficult to draw firm conclusions.

However, the rate of TM reported here was evaluated prospectively, and it was to a great extent similar to what has been reported in the literature. A second limitation was that the diagnosis of TM was only via CDUS with no histological confirmation. Finally, US monitoring of TM following varicocelectomy was not possible in four patients with TM who refused to attend during the followup visits, but this may not represent a major shortcoming as the current recommendations of the EAU state that the presence of microlithiasis alone is not an indication for a regular scrotal US ${ }^{[29]}$. Additionally, in the absence of other risk factors, TM is not an indication for biopsy or further US screening[ ${ }^{[37-39]}$.

\section{CONCLUSION}

This study demonstrated that only four of the 60 patients revealed intratesticular calcifications, and this was statistically insignificant. Moreover, there were also 23 healthy controls with subclinical varicoceles that were detected by scrotal duplex. However, TM was not detected in them. Thus, association of TM with varicocele is controversial. Finally, we recommend further studies to replicate this finding and to perform studies that compare fertile men and infertile patients with varicoceles to replicate this finding.

\section{CONFLICT OF INTEREST}

There are no conflicts of interest.

\section{REFERENCES}

1. Maturen KE. Attributable risk calculations for testicular microlithiasis. J Clin Ultrasound 2015; 43:120-121.

2. Xu C, Liu M, Zhang FF, Liu JL, Jiang XZ, Teng JB, et al. The association between testicular microlithiasis and semen parameters in Chinese adult men with fertility intention: experience of 226 cases. Urology 2014; 84:815-820.

3. Ravichandran S, Smith R, Cornford PA, Fordham MV. Surveillance of testicular microlithiasis? results of an UK based national questionnaire survey. BMC Urol 2006; 6:8.

4. Richenberg J, Brejt N. Testicular microlithiasis: is there a need for surveillance in the absence of other risk factors? Eur Radiol 2012; 22:2540-2546.

5. Lee S, Choi HJ. Double para-testicular cellular angiofibroma and synchronous testicular microlithiasis. J Pathol Transl Med 2016; 50:75-77.

6. Doherty FJ, Mullins TL, Sant GR, Drinkwater MA, Ucci AA. Testicular microlithiasis. A unique sonographic appearance. J Ultrasound Med 1987; 6:389-392. 
7. Fedder J. Prevalence of small testicular hyperechogenic foci in subgroups of 382 non-vasectomized, azoospermic men: a retrospective cohort study. Andrology 2017; 5:248-255.

8. Bach AM, Hann LE, Hadar O, Shi W., Yoo HH, Giess CS, et al. Testicular microlithiasis: what is its association with testicular cancer? Radiology 2001; 220:70-75.

9. Middleton WD, Teefey SA, Santillan CS. Testicular microlithiasis: prospective analysis of prevalence and associated tumor. Radiology 2002; 224:425-428.

10. Yee WS, Kim YS, Kim SJ, Choi JB, Kim SI, Ahn HS. Testicular microlithiasis: prevalence and clinical significance in a population referred for scrotal ultrasonography. Korean J Urol 2011; 52:172-177.

11. Savić G, Vasić V, Petrović M, Petrović J, Bašić D, Hadži-Đokić J. Testicular microlithiasis: Case report and literature review. Acta facultatis medicae Naissensis. 2017 Sep 1;34(3):241-5

12. Höbarth K, Susani M, Szabo N, Kratzik C. Incidence of testicular microlithiasis. Urology 1992; 40:464-467.

13. Pedersen MR, Møller H, Rafaelsen SR, Jørgensen MM, Osther PJ, Vedsted P. Characteristics of symptomatic men with testicular microlithiasis - a Danish cross-sectional questionnaire study. Andrology 2017; 5:556-561.

14. Cimador M, Castagnetti M, Gattuccio I, Pensabene M, Sergio M, De Grazia E.The hemodynamic approach to evaluating adolescent varicocele. Nat Rev Urol 2012; 9:247-257.

15. World Health Organization. The influence of varicocele on parameters of fertility in a large group of men presenting to infertility clinics. Fertil Steril 1992; 57:1289-1293.

16. Sakamoto H, Shichizyou T, Saito K, Okumura T, Ogawa Y, Yoshida H, et al. Testicular microlithiasis identified ultrasonographically in Japanese adult patients: prevalence and associated conditions. Urology 2006; 68:636-641.

17. Trussell JC, Haas GP, Wojtowycz A, Landas S, Blank W. High prevalence of bilateral varicoceles confirmed with ultrasonography. Int Urol Nephrol 2003; 35:115-118

18. Kobayashi H, Nagao K, Nakai T, Kudo T, Yoshida A, Hara $\mathrm{H}$, et al. Evaluation of testicular microlithiasis in varicoceles. Reprod Med Biol 2002; 1:75-79.
19. Stahl P, Schlegel PN. Standardization and documentation of varicocele evaluation. Curr Opin Urol 2011; 21:500-505.

20. Bennett HF, Middleton WD, Bullock AD, Teefey SA. Testicular microlithiasis: US follow-up. Radiology 2001; 218:359-363.

21. Richenberg J, Belfield J, Ramchandani P, Rocher L, Freeman S, Tsili AC, et al. Testicular microlithiasis imaging and follow-up: guidelines of the ESUR scrotal imaging subcommittee. Eur Radiol 2015; 25:323-330.

22. Kara T, Durmaz MS, Ceken K. Ultrasonography of tubular ectasia of the rete testis with associated scrotal findings. J Med Ultrason 2013; 40:27-32.

23. Dogra VS, Gottlieb RH, Oka M, Rubens DJ. Sonography of the scrotum. Radiology 2003; 227:18-36.

24. Sommers D, Winter T. Ultrasonography evaluation of scrotal masses. Radiol Clin North Am 2014; 52:1265-1281.

25. Schurich M, Aigner F, Frauscher F, Pallwein L. The role of ultrasound in assessmentof male fertility. Eur J Obstet Gynecol Reprod Biol 2009; 144(Suppl 1):S192-S198.

26. Chiou RK, Anderson JC, Wobig RK, Rosinsky DE, Matamoros A, Chen WS, et al. Color Doppler ultrasound criteria to diagnose varicoceles: correlation of a new scoring system with physical examination. Urology 1997; 50:953-956.

27. Belay RE, Huang GO, Shen JK, Ko EY. Diagnosis of clinical and subclinical varicocele: how has it evolved?. Asian J Androl 2016; 18:182-185.

28. Kocaoğlu M, Bozlar U, Bulakbaşi N, Sağlam M, Uçöz $\mathrm{T}$, Somuncu I. Testicular microlithiasis in pediatric age group: ultrasonography findings and literature review. Diagn Interv Radiol 2005; 11:60-65.

29. Jungwirth A, Diemer T, Dohle GR, Giwercman A, Kopa Z, Tournaye H, Krausz C. Guidelines in male infertility. European Association of Urology 2013.

30. Xu C, Zhang FF, Yang HL, Ma G, Zhang B, Li KJ, et al. The influence of testicular microlithiasis on the outcomes of in vitro fertilisation in a Chinese Han population. Andrologia 2017; 49:8.

31. Mahafza WS, Alarini MY, Awadghanem AF, Odwan G, Juweid ME. Testicular microlithiasis: correlation with Doppler sonography of testicular arteries and sperm function. J Clin Ultrasound 2016; 44:474-479. 
32. Thomas K, Wood SJ, Thompson AJ, Pilling D, Lewis-Jones DI. The incidence and significance of testicular microlithiasis in a subfertile population. Br J Radiol 2000; 73:494-497.

33. Clyne M. Asymptomatic testicular microlithiasis does not increase antisperm antibody production in infertile men. Nat Rev Urol 2012; 9:606-607.

34. Jiang H, Zhu WJ. Testicular microlithiasis is not a risk factor for the production of antisperm antibody in infertile males. Andrologia 2013; 45:305-309.

35. Sasagawa I, Nakada T, Kazama T, Satomi S, Katayama T, Matuda S. Testicular microlithiasis in male infertility. Urologia internationalis. 1988;43(6):368-9.
36. Aizenstein RI, Didomenico D, Wilbur AC, O’neil HK. Testicular microlithiasis: association with male infertility. J Clin Ultrasound 1998; 26:195-198.

37. DeCastro BJ, Peterson AC, Costabile RA. A 5-year followup study of asymptomatic men with testicular microlithiasis. J Urol 2008; 179:1420-1423.

38. Elzinga-Tinke JE, Sirre ME, Looijenga LH, van Casteren N, Wildhagen MF, Dohle GR. The predictive value of testicular ultrasound abnormalities for carcinoma in situ of the testis in men at risk for testicular cancer. Int J Androl 2010; 33:597-603.

39. Montgomery JS, Bloom DA. The diagnosis and management of scrotal masses. Med Clin North Am 2011; 95:235-244. 